\title{
DE PENÉLOPE A DILMA ROUSSEFF: MULHERES E ESTRUTURAS DE PODER NO PASSADO E NO PRESENTE
}

BeArd, Mary. Mulheres e poder: um manifesto. Tradução
de Celina Portocarrero. São Paulo: Planeta do Brasil, 20 i 8.

Vinícius Moretti Zavalis ${ }^{1}$

Sob a autoria da historiadora Mary Beard, chega ao público brasileiro, pela Editora Crítica, a obra Mulheres e poder: um manifesto, best-seller nos Estados Unidos e Inglaterra. Em sua arquitetura, o livro de Beard está organizado em um prefácio, dois ensaios divididos em dois capítulos, um posfácio, sugestóes de leitura, agradecimentos e uma lista de ilustrações. Os ensaios são resultado de duas palestras proferidas por Beard, nesta ordem, em 2014 e 2017, promovidas pela London Review of Book no Museu Britânico e, então, transmitida pela BBC. No primeiro ensaio, ela discute como as mulheres historicamente têm sido silenciadas, enquanto no segundo, os percalços de mulheres que ascenderam ao poder e o próprio conceito de poder. Tivéssemos que explicar o livro através de palavras-chave, sem dúvida sexo, gênero, poder, mulheres (sempre no plural), silenciamento, performance e mansplaining seriam algumas delas.

Nascida em 1955, na pequena cidade de Much Wenlok, Mary Beard é uma historiadora da arte britânica formada pela Universidade de Cambridge, que atua na área de Antiguidade. Em sua candidatura a Cambridge, sua escolha inicial foi o King's College, mas ela acabou desistindo pois a instituição não oferecia bolsas às mulheres, optando pela Newham College. Em Newham College, Beard se dedicou aos estudos clássicos e obteve os títulos de Bacharel em Artes, Mestre em Artes e $\mathrm{PhD}$ em Filosofia, com uma tese sobre religião romana em Cicero. Desde 1979, Beard é professora de Cambridge, primeiro

1 Bacharel e Licenciado em História pela Universidade do Estado do Rio de Janeiro (UERJ). Mestrando pelo Programa de Pós-Graduação em História Social da Universidade Federal Fluminense (PPGH-UFF), com pesquisa sobre a atuação política de Arsínoe II, no Egito, no século III, orientado por Alexandre Santos de Moraes. 
no King's, até 1983 , como a única professora mulher, e, depois, na Newham College, onde leciona até hoje na área de Clássicas. A produção de Beard vai desde livros sobre religião, arte e poder em Roma, até um blog sobre a vida acadêmica no Times Literary Supplement e documentários de Arqueologia Pública.

A formação de Mary Beard como militante feminista possui uma relação muito estreita com suas experiências sociais e profissionais enquanto mulher em uma sociedade masculina. Beard sofreu com o machismo institucional não só na sua candidatura ao King's College, mas no dia a dia acadêmico, quando colegas homens detraiam o potencial de mulheres como ela. Em Newham College, um braço da educação single sex de Cambridge, o que poderia parecer um ambiente segregador foi um laboratório para a formação política de Beard como militante. Entre as referências da teoria crítica feminista que influenciaram seu desenvolvimento pessoal, revelou Beard em uma entrevista, estão Kate Millet e, principalmente, Germaine Gree ${ }^{2}$. Atualmente, Beard considera, como comentou em outra entrevista ao The Cambridge Student: "Eu realmente não consigo entender o que seria ser uma mulher sem ser feminista" ${ }^{\text {. }}$

O livro é muito autoral, pois fala do lugar de Mary Beard como mulher nas relações de poder, mas é no prefácio que essa característica se sobressai conhecemos mais sobre ela nele. Beard usa a história de sua mãe, Joyce Emily Beard, uma diretora escolar, que viu mudanças significativas para as mulheres no século XX, para apresentar e explicar os objetivos do livro. A autora afirma que apesar de não ter conseguir ir à universidade, a posição de direção da sua mãe foi a personificação do poder para muitos meninos e meninas sob a sua responsabilidade. Ao fazer essa analogia, ela recorda a existência de múltiplas maneiras de conceituar poder, não apenas como poder político, mas como liderança, como ela aborda adiante, no capítulo dois. Beard finaliza dizendo que gostaria de ter tido a chance de explicar para sua mãe, já falecida, os termos de seu livro, que muito diz respeito sobre ela, a saber:

[...] até que ponto estão profundamente incorporados à cultura ocidental os mecanismos que silenciam as mulheres, que se recusam a levá-las a sério e que as afastam (às vezes literalmente, como veremos) dos centros de poder. Esse é um dos pontos em que o mundo dos antigos gregos e romanos ajuda a esclarecer o nosso. No que diz

2 The Guardian. The book that made me a feminist. 2017. Disponível em: < https:// www.theguardian.com/books/2017/dec/16/book-that-made-me-a-feminist $>$. Acesso em $11 / 05 / 2018$.

3 CHHIBBER, ASHLEY. Inverview: Mary Beard. 2013. Disponível em: < https://www.tcs. cam.ac.uk/interviews/0028855-interview-mary-beard.html>. Acesso em: 11/05/2018. 
respeito a silenciar as mulheres, a cultura ocidental tem milhares de anos de prática (BEARD, 2018, pp. 10-11).

A metáfora de Penélope, construída por Mary Beard, com base em um episódio da Odisseia, resume de maneira muito feliz os objetivos da autora na construção do capítulo um. Telêmaco, filho de Odisseu, silenciou Penélope, ao mandar que ela voltasse aos seus aposentos para tear e rocar, tarefas ditas femininas, porque o discurso público era uma tarefa masculina. O exemplo de Telêmaco foi apenas um entre os vários outros tratados pela autora, seja usando fontes da Antiguidade, ou fontes atuais, sobretudo imagéticas, do silenciamento das mulheres. Existiria uma dicotomia, segundo a autora, do masculino-feminino, fraco-forte, voz grossa-voz estridente, públicoprivado, masculinidade-feminidade, presente desde a Antiguidade até hoje. Se o discurso está relacionado, na nossa tradição cultural, ao espaço público, excluir as mulheres significa excluí-las do poder, o que explica sua falta de representatividade política. ${ }^{4}$

O capítulo dois do livro aborda representaçóes antigas e contemporâneas de mulheres que alcançaram lugares e tarefas públicas, ainda que dentro de um sistema de valores masculino. Para a representação das mulheres antigas, Beard abordar os casos de Lisístrata, Clitemnestra, Atena e das Amazonas, enquanto para as modernas Ângela Merkel, Hillary Clinton e outras. Beard argumenta que, devido ao fato de nossas premissas culturais sobre poder serem masculinas, essas mulheres utilizam táticas e estratégias masculinas para exercer um poder. Usando roupas masculinas, como a calça, ou estratégias de retórica, como engrossar a voz, elas esperam que a sociedade governada reconheça nelas porta-vozes legítimas do poder público. Beard conclui que as mulheres não devem se adaptar a esses códigos para chegar ao poder, pois isso não modifica essencialmente as estruturas de poder masculino nem dá voz às mulheres.

Mary Beard segue discorrendo sobre como as mulheres poderiam subverter essa ordem que as silencia e as afasta do poder - entendido no senso comum como atuação pública. Segundo Beard não são as mulheres que devem se encaixar e mudar comportamentos para chegar ao poder, tampouco a mudança ocorrerá com ações individuais, mas modificando as estruturas. Segundo Beard, não adianta essas mulheres inserirem-se na estrutura

4 Mary Beard argumenta que a sub-representação das mulheres na política é efeito de uma construção discursiva, que perpassa a nossa cultura, de silenciá-las. E esse silenciamento, por sua vez, não ocorre ao acaso, mas é uma maneira de os homens exercerem poder sobre as mulheres (BEARD, 2018, p. 43). 
masculina, mas continuar reproduzindo-a, porque, ao fazê-lo, garantem a continuidade histórica da estrutura no tempo. Para mudá-las, a autora considera ser necessário (re)pensar o poder de outra forma, que não apenas associado ao prestígio político, sob a lógica masculina, mas como liderança ou atributo. Beard propõe que as mulheres ocupem os espaços e coletivamente proponham a denúncia e a desconstrução das estruturas, reivindicando discursos políticos para mudar o status quo.

Uma questão importante chama a atenção do leitor brasileiro no capitulo dois, quando Mary Beard aborda a figura da ex-presidente Dilma Vanna Rousseff como mulher de poder. Beard relembra o episódio em que Rousseff foi comparada à Medusa de Caravaggio em uma foto, notando que esse mito simboliza o domínio masculino sobre o poder ilegítimo feminino. Anos depois da foto, Rousseff enfrentou um impeachment posto suas pedaladas orçamentárias - manipulação contábil que mascara o déficit público, praticadas antes por outros presidentes. A forma como o processo foi executado e as críticas ${ }^{5}$ à competência de Rousseff demonstram que a oposição ao seu governo se deve, em maioria, à cisma da direita com mulheres no poder. É provável que o processo de impeachment tivesse sido sensivelmente diferente caso o presidente investigado não fosse uma mulher, vide o exemplo do presidente Michel Temer. ${ }^{6}$

Como um arco de palestras, o manifesto de Mary Beard termina em aberto, sem uma conclusão, mas com um posfácio, em tom explicativo, que justifica a configuração dos ensaios. Nele, a autora explica a organização das palestras que deram origem ao livro, o fato de não ter feito mudanças drásticas nos textos originais e atualiza alguns dados apresentados nos ensaios. Esclarece também que ela não conseguiu desenvolver sua ideia de reconfiguração do conceito de poder para pensar a atuação das mulheres, dando espaço para uma porvindoura reflexão. Beard comenta brevemente sobre exemplos mais recentes dos tipos de abusos que as mulheres podem sofrer online, com base no caso da deputada trabalhista Diane Abott vs Boris Johnson. Ela finaliza

5 Em edições futuras, seria útil se Mary Beard analisasse o tema, tomando como exemplo o adesivo misógino de Rousseff de pernas abertas nas bombas de gasolinas dos carros - uma alusão à penetração, que criticava o aumento no preço do combustível. Mesmo com aumentos progressivos no atual governo de Michel Temer, não existem adesivos semelhantes representando Temer de pernas abertas, o que demonstra a misoginia da direita brasileira.

6 Cf. GATINOIS, Claire. Les préjugés envers les femmes ont joué de manière évidente dans la destitution de Dilma Rousseff. 2016. Disponível em: http://www.lemonde.fr/idees/ article/2016/05/19/les-prejuges-envers-les-femmes-ont-joue-de-maniere-evidente-dans-ladestitution-de-dilma- rousseff_4922493_3232.html?xtmc=petrobras\&xtcr=1>. Acesso em 11/05/2018. 
o posfácio ressaltando a necessidade de remontarmos ao passado como uma arqueologia do inconsciente androcêntrico, que da Antiguidade até hoje, silencia as Penélopes.

Em suma, Mary Beard aborda de forma inovadora, seja pela escrita leve empregada, pela variedade de fontes analisadas ou por seu amplo recorte, a relação entre mulheres e poder. Ela sintetiza que historicamente, desde Antiguidade até nossos dias, as mulheres são silenciadas pelos homens, o que se reflete na divisão sexual de tarefas que as afasta dos espaços de poder. Como solução, ela sugere não só ocupar os espaços, tal qual repensar o próprio conceito de poder, pois ele é concebido, no senso comum, a partir da visão masculina relacionado à política. Mais importante que sua análise, a qual deixa mais perguntas que respostas, é a proposta de um livro de grande circulação que divulga os debates da História das Mulheres da década de 70. Em tempos de impeachment, "Escola Sem Partido" e de "ideologia de gênero", o livro Mulheres e poder: um Manifesto, tão bem aceito entre os britânicos, chega em boa hora ao Brasil. 